\title{
Engaging with ELL Students in Their Personal Writing
}

\author{
Esther Chung \\ Teachers College, Columbia University
}

I am currently a student teacher at a charter school in Philadelphia, Pennsylvania. My class is a self-contained $7^{\text {th }}$ and $8^{\text {th }}$ grade ELL classroom, where the cooperating teacher (CT) teaches all content classes. In English Language Arts (ELA) this month, students were assigned to write a personal friendship story. Prior to writing, students were asked to fill out a graphic organizer with three columns: (1) My Friends, (2) Places I have Friends, and (3) Things I like to do with Friends. I worked with two emergent/transitioning level students in separate Zoom breakout rooms as they filled out their charts. One student is a refugee from Burundi, Africa, but is ethnically Congolese. She came to the U.S. last year, in the first semester of the 2019-2020 school year. The other student is a refugee from Tanzania, who came to the U.S. around the same time, but became a registered student in March of 2020, just before the pandemic hit.

Under the column for "Things I Like to do with Friends," my student from Burundi wrote, "Washing dishes." I responded in surprise, "You like to wash dishes with your friends?" I thought about how I loathed doing the dishes at her age and did everything I could to escape it. I could just hear my parents' frustration with me whenever I plopped my dishes in the sink after dinner and headed for my room. I chuckled aloud. I couldn't imagine how washing dishes was a favorite pastime of hers.

"Yes, let me show you how we wash dishes," my student responded. She shared the following screen on Google Images:

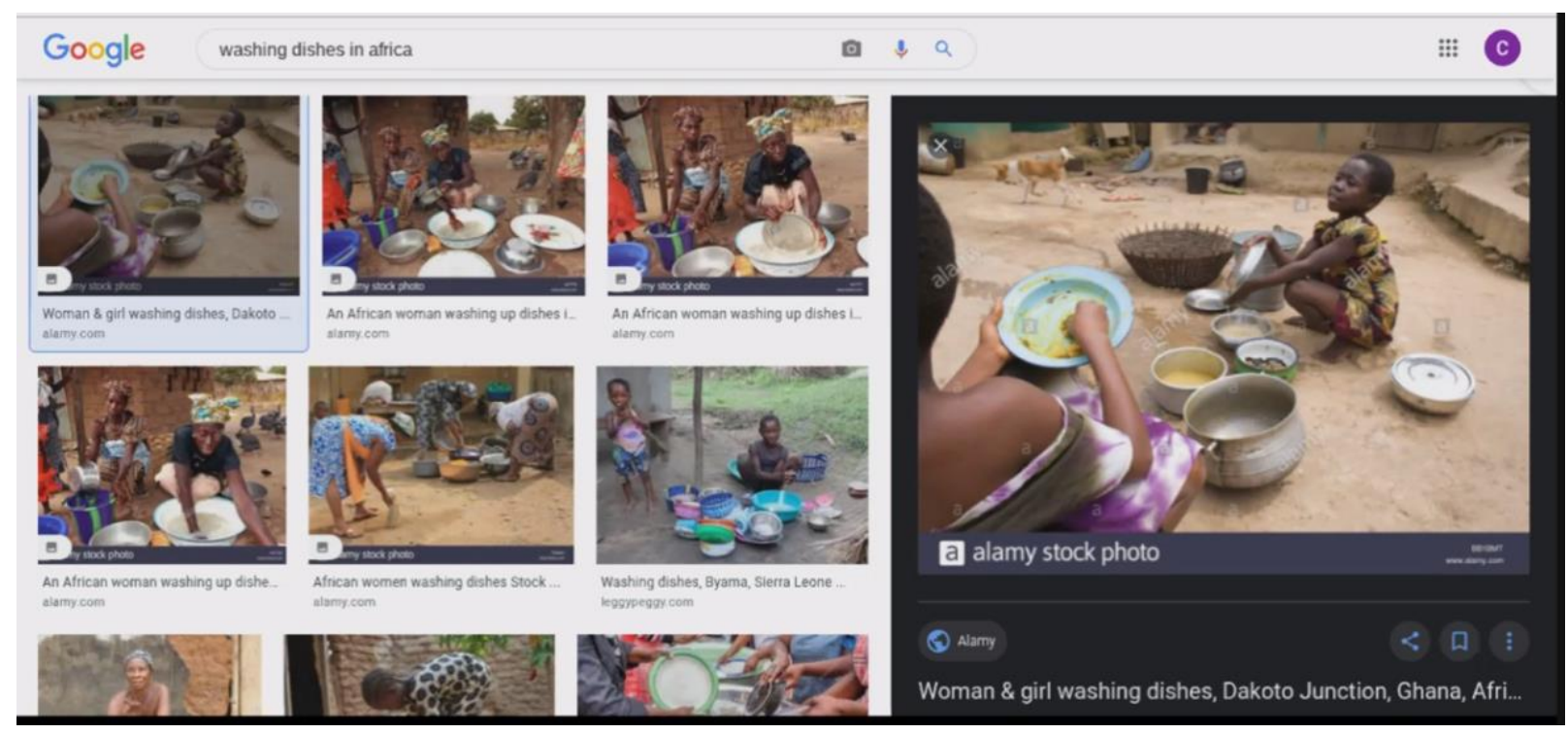

(C) 2021 Chung. This is an open access article distributed under the terms of the Creative Commons Attribution License, which permits the user to copy, distribute, and transmit the work provided that the original authors and source are credited. 
I then understood. She enjoyed washing the dishes because it was a social community activity amongst the women. Just as I walked away from the dishes to socialize with my friends on the internet, she walked towards the dishes in Burundi to socialize with her friends too. I followedup with another question to bring out more language:

$M e$ : "What kind of things do you say or do when you wash dishes together? What does it sound like?"

Student: "Joke. We joke around."

After this, I hopped over to a breakout room with my other student from Tanzania. Under the column for "Places I Have Friends," she wrote three bullet points: Tanzania, Nyarugusu, Arusha.

$M e:$ "Is Nyarugusu another city in Tanzania?"

Student: "No, it's a country. Let me show you on Google."

When she shared her screen, I realized that she was referring to her refugee camp in Tanzania. It wasn't that I didn't know my students were living in refugee camps before being resettled in America. I just didn't think of the fact that my students did have friends there and most likely still think of them. Of course! They must miss their friends, especially this student from Tanzania. She was a student in an American school building for less than a month. Then, the pandemic hit and schools went fully remote. She must not have many friends here. It's been nearly three semesters since she stepped into a building surrounded by peers.

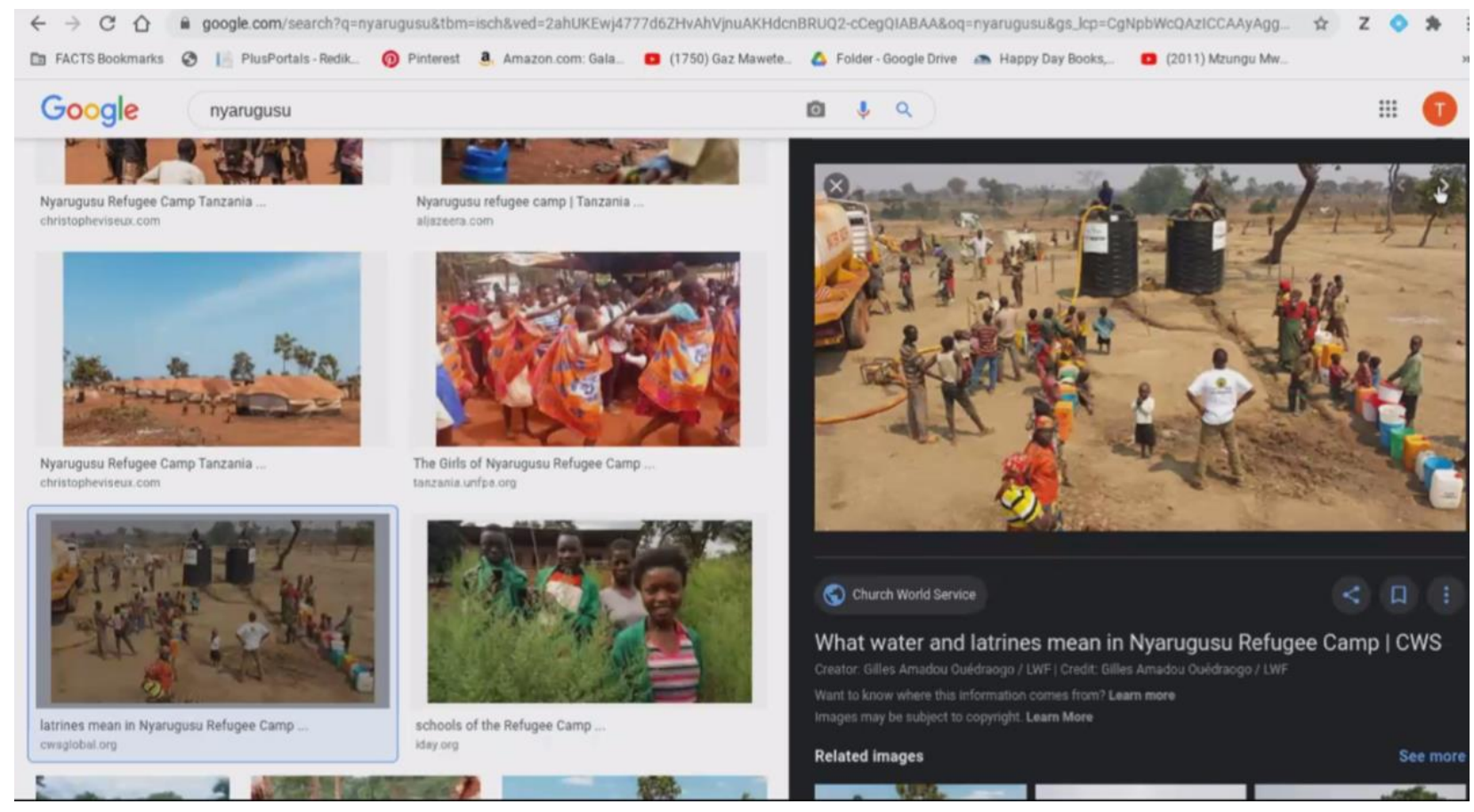


Sometimes I feel as if I am hopping from country to country when I assist students in their personal writing. It naturally piques my own curiosity and makes my days interesting. However, I want to be cautious and respectful when I engage with the lives of my students. I must be mindful of my verbal responses and my body language when students share. My reaction should not make them feel as if they should feel negatively about their lives - or even worse, that I am judging them. The life experiences that our students carry from their refugee camps and villages are their funds of knowledge, which vibrantly colors our classroom and community. When we give our students the space to process and record their funds of knowledge through writing, we validate their experiences and create a richer learning experience for them.

Esther recently completed two semesters of virtual student teaching in Philadelphia with 3rd, 7th, and 8th grade students. She looks forward to starting her career as an ELL teacher this Fall 2021. Correspondence should be sent to E-mail: emc2258@tc.columbia.edu 